\title{
SCIDOC
}

International Journal of Dentistry and Oral Science (IJDOS)

ISSN: 2377-8075

\section{Evaluation Of Risk Factors and Biological Markers Related To Oral Epithelial Dysplasia and Squamous Cell Carcinoma: Case Control Study}

Research Article

\section{Rabab I Salama ${ }^{1 *}$, Amal El Deeb ${ }^{2}$, Hoda A Fansa ${ }^{3}$}

${ }^{1}$ Assistant Professor of Dental Public Health and Preventive Dentistry, Faculty of Dentistry, Mansoura University.

${ }^{2}$ Professor of Oral Pathology, Faculty of Dentistry, Tanta University, Tanta, Egypt. Affiliated to Faculty of Dentistry, Umm Al Qura University, Makkah, KSA.

${ }^{3}$ Assistant professor of Oral Biology, Faculty of Dentistry, Alexandria University.

\section{Abstract}

Background: Oral squamous cell carcinoma is recognized as a public health concern worldwide. It is the sixth most common malignancy which recorded $90 \%$ of all oral malignant tumors causing a significant number of cancer related death every year. The late diagnosis and lack of specific biomarkers for predicting the tumor progression and patient's prognosis could be the cause of the high mortality rate.

Objectives: To assess the oral epithelial dysplasia and squamous cell carcinoma (OSCC) risk factors and evaluate immunohistochemically the over expression of P53 in cases of oral epithelial dysplasia and OSCC and correlate it with the expression of the immune cell infiltrate (CD4 and CD8) in the same lesions.

Methodology: A case control study was conducted on (25) cases of oral epithelial dysplasia and (35) case with oral squamous cell carcinoma compared with (240) participants as a control group who was matched with age gender and smoking status. Data were collected by interview administrated questionnaire, clinical examination and immunohistochemistry. The immunohistochemistry was done on (60) samples from cases and (60) randomly samples from control group.

Results: Smoking, oral hygiene practice and periodontal conditions considered risk factors for oral cancer. The expression of CD4+ and CD8+ was increased with the transformation from normal epithelium to dysplastic epithelium and squamous cell carcinoma, this expression was significantly correlated with P53 immunostaining at $\mathrm{p}(<0.000)$.

Conclusion: The most detected risk factors related to OSCC were the frequency and duration of smoking, bad oral hygiene, sever periodontitis and low educational level. Public awareness is needed among these targeted groups to prevent oral cancer. The increase in the expression of CD4+, CD8 + with epithelial transformation from normal to dysplastic or squamous cell carcinoma and its correlation with the over expression of P53 may have a potential significant role as biological markers of malignant transformation and carcinogenesis, and it could potentially be utilized in the treatment of oral squamous cell carcinoma.

Keywords: Epithelial Dysplasia; Oral Squamous Cell Carcinoma; P53; CD4 and CD8.

\section{Introduction}

The oral squamous cell carcinoma is recognized as a public health concern worldwide. It is the sixth most common malignancy which account $90 \%$ of all oral malignancies causing a significant number of cancer related death every year [1]. Assessment of future preventive strategies is of high clinical relevance. This could lead to the recognition of the pre-malignant oral lesions and its malignant transformation at initial stages with a positive impact on the outcome. The etiology of oral squamous cell carcinoma

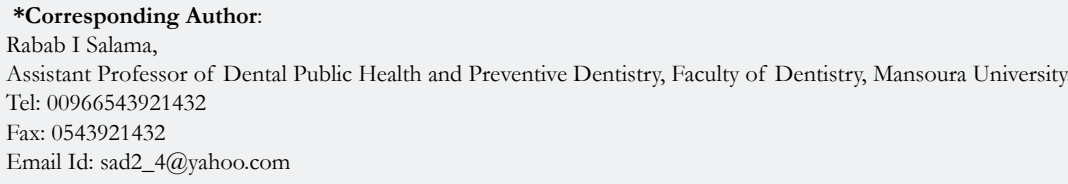

Citation: Rabab I Salama, Amal El Deeb, Hoda A Fansa. Evaluation Of Risk Factors and Biological Markers Related To Oral Epithelial Dysplasia and Squamous Cell Carcinoma: Case Control Study. Int J Dentistry Oral Sci. 2021;08(05):2671-2680. doi: http://dx.doi.org/10.19070/2377-8075-21000522

Copyright: Rabab I Salama 2021. This is an open-access article distributed under the terms of the Creative Commons Attribution License, which permits unrestricted use, distribution and reproduction in any medium, provided the original author and source are credited. 
is multi- factorial; genetic, environment, social and behavioral effects may all be implicated [2].

Regarding the etiological factors, smoking consumption is widely recognized as major risk factor for oral malignancies [3]. Previous epidemiological studies have provided evidence of the effect of oral health status and oral hygiene practices on the development of oral malignancies. Poor oral hygiene seems to cause additional oral cancer risks. Irregular tooth brushing, dental prostheses, and use of oral hygiene measures have all been associated with development of oral cancer $[4,5]$.

Higher proportion of cases of OSCC develop from premalignant lesions such as leukoplakia. The late diagnosis and lacking of specific predictive biomarkers for tumor progression and patient's prognosis could be the cause of the high mortality rate of OSCC [6-8].

The histological tissue examination is the gold standard for diagnosis of the malignant transformation of oral lesions. One of the fundamentals in reducing the cost of treatment, and high morbidity associated with OSCC is the identification of high-risk oral premalignant lesions. Molecular biological markers evaluation was recorded as a very useful methods in the diagnosis and prognostic evaluation of premalignant lesions [6].

The cancerization process is attributed to clinical, molecular and immunological factors, immune system and cancer are mutually related as tumors development are potentially immunogenic [9]. Studies of the cancer-immune system interactions have revealed that every known innate and adaptive immune effector mechanism aids in the tumor recognition and control process [10]. Adaptive immunity's effectors such as CD4+ helper T cells, CD8+ cytotoxic $\mathrm{T}$ cells, and antibodies are specifically targeted the tumor antigens. Tumor antigens are molecules expressed only in tumor cells are normal cellular proteins that are abnormally expressed as a result of genetic mutations, quantitative differences in expression, or differences in post translational modifications [10].

The immune suppression, both systemically and at the site of the tumor is a characteristic feature of squamous cell carcinoma of head and neck (SCCHN) patients. Increased levels of circulating $\mathrm{T}$ regulatory cells and CD34+ progenitor cells have been shown to suppress CD8+ T cell-mediated immunity and are associated with a poorer prognosis $[11,12]$. There is also evidence that premalignant lesions are characterized by an influx of proinflammatory immune cells, including NK cells, macrophages, and CD8+ $\mathrm{T}$ cells and that $\mathrm{CD} 8+\mathrm{T}$ cells are more activated in premalignant oral tissue $[13,14]$.

Multiple proto-oncogenes and tumor suppressor genes including p16, cyclin D1, P53 and EGFR are involved in the oral carcinogenesis process. P53 is a tumor suppressor gene located on chromosome 17p. Mutations of P53 gene is one of the most common events in human carcinogenesis. As mutated protein is not easily digestible, therefore it accumulates inside the cancer cell resulting in immunohistochemical over expression. In OSCC, over expression of P53 is considered a marker of poor prognosis and may result in decreased sensitivity of tumor cells to chemotherapeutic drugs $[6,9]$.

Many studies reported that, up to $75 \%$ of oral squamous carci- noma could be prevented by avoiding environmental factors, particularly the consumption of tobacco and improved diagnostic methods [2-8]. Therefore, this study aimed to assess the epithelial dysplasia and OSCC risk related factors and evaluate immunohistochemically over expression of P53 in cases of oral epithelial dysplasia and OSCC and correlate it with the expression of the immune cell infiltrate (CD4 and CD8) in the same lesions.

\section{Materials and Methods}

\section{Case's Selection}

The present study was designed as case control study on patient with epithelial dysplasia or with oral squamous cell carcinoma recruited from two oncology centers (Tanta cancer institute and Damietta Oncology Center) and from oral surgery and oral pathology department, faculty of dentistry, Tanta university. All the medical records of patients with epithelial dysplasia or with oral squamous cell carcinoma (OSCC) were revised and the freshly diagnosed cases (at the late three months) with contact phone number or address were selected to be included in the study. Only (60) patients, (26) female patients and (34) male patients who signed informed consent and approved to use their data, were included in this study.

\section{Control's Selection}

The control participants were selected from the out-patient's clinic, Damietta General Hospital. A total of (240) patients who approved to participate in this study, were recruited with matching procedure by age, gender, and smoking habits which was done to finalize the selection of the control group. Control participants with systemic diseases or with oral premalignant or malignant lesions or any type of cancer were excluded. The control group after matching procedure was consisted of: (64) female participants with and age range from 40 - 60 years, non-smokers, (61) male participants, non - smokers with and age ranged from $40-80$ years and (115) smoker males with and age ranged from $40-80$ years.

\section{Data Collection}

Data was collected by interviewer administrated questionnaire, reviewed patients' medical records, clinical examination and immunohistochemical examination.

Before starting the study, the questionnaire was piloted to (20) participants from the cases and control groups and some modifications to it was performed according to the feedback. Thequestionnaire was applied to all cases and control participants by face-to-face interview. The questionnaire included data about the demographic characters in addition to smoking habits and its duration and oral hygiene practice measures. Data related to the epithelial dysplasia histological grade, oral squamous cell carcinoma clinical site or stage, lymph node metastasis or distant metastasis were recorded from the medical records.

The Clinical Examination: To ensure the validity of clinical examination data, one examiner was trained and calibrated for all examined clinical criteria. The examiner who was blind to differentiate between the cases and the controls, examined dental and oral 
status for all participants, the presence of oral fixed or removable prosthodontics appliance were recorded. Periodontal conditions and teeth mobility were evaluated by Russell index [15].

Tissue Blocks Preparation: Sixty paraffin embedded lesions previously diagnosed as epithelial dysplasia (25) and OSCC (35) were examined after ethical approval from the patients. Newly prepared (60) paraffin embedded healthy tissue from the control patients ( 24 from females and 36 from males) were prepared after approval from the patients.

Immunohistopathological Examination: From each paraffin-embedded block $5 \mu \mathrm{m}$ thick sections were cut and routinely stained with H\&E (Hematoxylin and Eosin), then analyzed using light microscopy to confirm the diagnosis. Two independent oral pathologists examined the stained sections and determine histological grades of epithelial dysplasia (Mild, moderate and severe dysplasia) according to World Health Organization (WHO) criteria, similarly, OSCC cases were examined and differentiated histologically in to (poorly, moderate and well differentiated) [16].

Immunostaining: Paraffin-embedded biopsies were cut in to $4 \mu \mathrm{m}$ thick sections. The sections were mounted on recharged slides, deparaffinized, and rehydrated. Antigen retrieval was performed by placing the slides in citrate buffer at $95^{\circ} \mathrm{C}$ for 5 minutes (4-5 times). Then the slides were cooled to room temperature. Washing the slides with wash buffer (phosphate buffer solution, PBS,), then block the slides with $(0.3 \%$ hydrogen peroxide in methanol) for 10 minutes. Primary antibodies [monoclonal mouse anti CD4 antibody (ZYMED, CA, USA.), monoclonal mouse anti CD8 antibody (DAKO, CA, USA) and antihuman P53 protein (DAKO, CA, USA)] were added and incubated for 30 minutes. The slides were washed and secondary antibody was applied for 30 minutes. HRP (horse radish peroxidase enzyme polymer) reagent was applied for 30 minutes and the slides were washed in wash buffer for 5 minutes (two times). Di-acetyl bromo acetic acid (DAB) was added to the slide for 3-4 minutes and washed with buffer. The slides were dipped in Mayor's hematoxylin for less than a minute and washed in running tap water. Finally, the slides were dehydrated in ascending grades of alcohol and then to xylene. Mountex (Histolab AB, Gothenburg, Sweden) was used to permanently mount slides. Sections from tonsils served as positive controls, while omission of primary antibodies served as negative controls.

Immunohistochemical Staining Evaluation: All the slides were evaluated with an optical microscope Olympus B $\times 41$ (Olympus, Tokyo, Japan) by two independent pathologists who were unaware of the clinical characteristics of the samples. Evaluation of immunohistochemical expression of CD4, CD8 and P53 was performed as follows: Five microscopic fields were randomly selected, and the percentage of the stained cells (cytoplasmic or nuclear staining) were evaluated. All histopathological and immunohistochemical samples included were categorized into three groups such as normal oral mucosa (normal control) group, oral epithelial dysplasia group and OSCC group. The parameters used to analyze the expression of P53 protein and CD4, CD8, are: 1) pattern of distribution of positive cells in the epithelial layers and sub-epithelial stroma in cases of epithelial dysplasia and at the tumor invasion front (neoplastic nests and peritumoral stroma)in cases of OSCC, 2) the percentage of positive cells. The staining intensity was graded upon microscopic examination based on the number of positive cells using a 3-grade scoring: 0 (No staining cells), 1 (week staining=if the positive cells comprised less than 20\%), 2 (moderate staining $=$ positive cells $: 20-50 \%$ ), 3 (strong staining $=$ positive cells more than $50 \%$ ).

\section{Statistical Analysis}

The statistical analysis was performed using SPSS software version 20. Frequencies were calculated and chi square test was performed to compare between the frequencies. Multiple regression and odds ratio were calculated. P value equal or less than 0.05 was considered significance.

\section{Results}

This was a case control study designed to evaluate immunohisto-

Graph 1. Percentages of oral sites distribution of epithelial dysplasia and oral squamous cell carcinoma lesions.

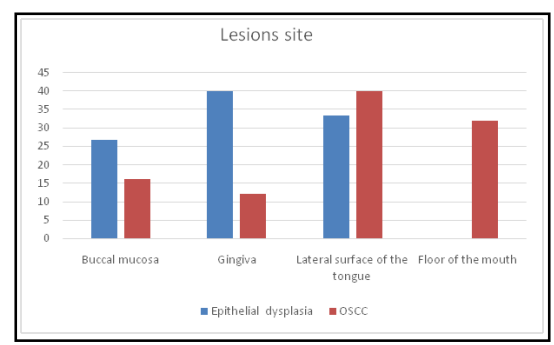

Graph 2. Percentages of clinical stages and histological differentiation of the oral squamous cell carcinoma (OSCC) patients.

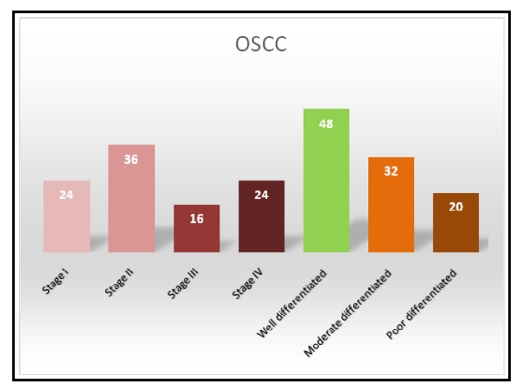


chemically the over expression of P53 in cases of oral epithelial dysplasia and oral squamous cell carcinoma and correlated it with the expression of the immune cell infiltrate (CD4 and CD8) in the same lesions, in addition to evaluate the risk factors related to oral epithelial dysplasia and oral squamous cell carcinoma. A total of (300) patients (240) as control and (60) as cases were included in this study, all cases and controls answered the questionnaire and subjected to oral examinations. For histopathological examinations, all the cases were examined while a randomly selected (60) participants from the control group matched with the cases were included. The lesions sites among epithelial dysplasia and OSCC patients were explained in graph (1) where the histopathological tissues were collected, gingival tissue samples were collected from the (60) participants in control group. Among the OSCC patients the stages of tumor and the histopathological differentiation were mentioned in graph (2).

Regarding the demographic characters for the cases and control groups, the percentages of males and females in the control and cases groups were equally with no significance difference between

Table 1. Demographic characters, oral conditions, smoking status and duration among cases and control patients.

\begin{tabular}{|c|c|c|c|c|}
\hline \multirow[t]{2}{*}{ Variable } & $\begin{array}{l}\text { Control } \\
\text { N (\%) }\end{array}$ & $\begin{array}{c}\text { Epi dysplasia } \\
\text { N (\%) }\end{array}$ & $\begin{array}{l}\text { OSCC } \\
\text { N }(\%)\end{array}$ & \multirow[t]{2}{*}{$P$ value } \\
\hline & -240 & -25 & -35 & \\
\hline \multicolumn{5}{|c|}{ Gender } \\
\hline Male & $176(73.3 \%)$ & $18(72 \%)$ & $26(74.3 \%)$ & \multirow{2}{*}{0.09} \\
\hline Female & $64(26.7 \%)$ & $7(28 \%)$ & $9(25.7 \%)$ & \\
\hline \multicolumn{5}{|l|}{ Age groups } \\
\hline $40-50$ & $108(45 \%)$ & $11(44 \%)$ & $16(45.7 \%)$ & \multirow{3}{*}{0.125} \\
\hline $50-60$ & $51(21.2 \%)$ & $5(20 \%)$ & $7(20 \%)$ & \\
\hline$>60$ & $81(33.8 \%)$ & $9(36 \%)$ & $12(34.3 \%)$ & \\
\hline \multicolumn{5}{|c|}{ Educational level } \\
\hline Low & $96(40 \%)$ & $12(48 \%)$ & $17(48.6 \%)$ & \multirow{3}{*}{0.06} \\
\hline Moderate & $73(30.4 \%)$ & $8(32 \%)$ & $13(37.1 \%)$ & \\
\hline High & $71(29.6 \%)$ & $5(20 \%)$ & $5(14.3 \%)$ & \\
\hline \multicolumn{5}{|c|}{ Teeth brushing (no /day) } \\
\hline No use & $2(0.8 \%)$ & $14(56 \%)$ & $27(77.1 \%)$ & \multirow{4}{*}{$<0.000^{*}$} \\
\hline Once daily & $42(17.5 \%)$ & $7(28 \%)$ & $6(17.1 \%)$ & \\
\hline Twice daily & $102(42.5 \%)$ & $3(12 \%)$ & $2(5.7 \%)$ & \\
\hline More twice than daily & $94(39.2 \%)$ & $1(4 \%)$ & - & \\
\hline \multicolumn{5}{|c|}{ Periodontal conditions } \\
\hline Normal & $153(63.8 \%)$ & - & - & \multirow{5}{*}{$<0.000^{*}$} \\
\hline Mild & $75(31.3 \%)$ & - & - & \\
\hline Moderate & $10(4.1 \%)$ & $2(8 \%)$ & - & \\
\hline Sever & $2(0.8 \%)$ & $14(56 \%)$ & $23(65.7 \%)$ & \\
\hline Tooth mobility & - & $9(36 \%)$ & $12(34.3 \%)$ & \\
\hline \multicolumn{5}{|c|}{ Prosthodontic appliance } \\
\hline No appliance & $198(82.5 \%)$ & $3(12 \%)$ & $5(14.3 \%)$ & \multirow{4}{*}{$<0.000^{*}$} \\
\hline Fixed & $12(5 \%)$ & - & - & \\
\hline Removable partial denture & $30(12.5 \%)$ & $20(80 \%)$ & $14(40 \%)$ & \\
\hline Complete denture & - & $2(8 \%)$ & $16(45.7 \%)$ & \\
\hline \multicolumn{5}{|c|}{ Smoking status (Duration) } \\
\hline Non - smoker & $170(70.8 \%)$ & $4(16 \%)$ & $6(17 \%)$ & \multirow{4}{*}{$<0.000^{*}$} \\
\hline Current smokers $(<5$ years $)$ & $12(5 \%)$ & - & - & \\
\hline Current smokers ( $5-10$ years) & $27(11.3 \%)$ & $8(32 \%)$ & $12(34.3 \%)$ & \\
\hline Current smokers ( $>10$ years) & $31(12.9 \%)$ & $13(52 \%)$ & $17(48.6 \%)$ & \\
\hline \multicolumn{5}{|c|}{ Smoking frequency (Pack/ day) } \\
\hline$<5$ & $25(10.4 \%)$ & - & - & \multirow{3}{*}{$<0.000^{*}$} \\
\hline $5-10$ & $17(7.1 \%)$ & $5(20 \%)$ & $7(20 \%)$ & \\
\hline$>10$ & $28(11.7 \%)$ & $16(64 \%)$ & $22(62.9 \%)$ & \\
\hline
\end{tabular}


the three groups $(\mathrm{p}=0.09)$. The age distribution among the control and cases groups showed no significance difference $(\mathrm{p}=$ 0.125). Educational level was varying from low to high level, control group showed high percent $(29.6 \%)$ of high educational level compared with (14.3\%) among OSCC, no significance difference was found $(p=0.06)$. Using of tooth brush was noticed with high percentages for twice or more than twice daily $(42.5 \%$ and $39.2 \%$ respectively) among control group. On the other hand, epithelial dysplasia group showed high percentages of no brush usage or use it once (56\% and $28 \%$ respectively) which was similar to that among OSCC group (77.1\% and 17.1\%). Significant difference was found $(p<0.000)$ between the three groups regarding the teeth brushing number per day. Regarding the periodontal conditions, mild and moderate periodontitis were observed with high percentages (63.8\% and $31.3 \%$ respectively) among control group. Mild periodontitis was not observed among cases with epithelial dysplasia and OSCC while, sever periodontitis and tooth mobility were recorded with high percentages $(56 \%, 36 \%, 65.7 \%$ and

Table 2. The multiple logistic regression models of different variables, Odds Ratio (OR), 95\% confidence interval and pvalues.

\begin{tabular}{|c|c|c|c|}
\hline Variable & $\mathbf{O R}^{*}$ & $\begin{array}{c}\text { CI } \\
(95 \%)\end{array}$ & $P$ value \\
\hline \multicolumn{4}{|c|}{ Gender } \\
\hline Female & 1 & - & \multirow{2}{*}{$0.05^{*}$} \\
\hline Male & 1.9 & $0.5-2.9$ & \\
\hline \multicolumn{4}{|l|}{ Age groups } \\
\hline $40-50$ & 1 & - & \multirow{3}{*}{0.09} \\
\hline $50-60$ & 0.7 & $0.4-1.8$ & \\
\hline$>60$ & 0.9 & $0.5-2.1$ & \\
\hline \multicolumn{4}{|l|}{ Educational level } \\
\hline High & 1 & - & \multirow{3}{*}{$0.01^{*}$} \\
\hline Moderate & 0.9 & $0.8-5.6$ & \\
\hline Low & 2.3 & $0.2-4.8$ & \\
\hline \multicolumn{4}{|l|}{ Teeth brushing (no/day) } \\
\hline More than twice daily & 1 & - & \multirow{4}{*}{$<0.000^{*}$} \\
\hline Twice daily & 1.2 & $0.5-3.2$ & \\
\hline Once daily & 2.7 & $0.9-4.5$ & \\
\hline No use & 4.3 & $1.1-7.2$ & \\
\hline \multicolumn{4}{|l|}{ Periodontal conditions } \\
\hline Normal & 1 & - & \multirow{5}{*}{$0.001^{*}$} \\
\hline Mild & 0.8 & $0.4-3.8$ & \\
\hline Moderate & 2.5 & $0.5-5.7$ & \\
\hline Sever & 3.8 & $1.2-7.7$ & \\
\hline Tooth mobility & 5.9 & $2.7-10.8$ & \\
\hline \multicolumn{4}{|l|}{ Prosthodontic appliance } \\
\hline No appliance & 1 & - & \multirow{4}{*}{0.09} \\
\hline Fixed & 0.6 & $0.3-1.2$ & \\
\hline Removable partial denture & 0.9 & $0.5-1.7$ & \\
\hline Complete denture & 0.7 & $0.5-1.9$ & \\
\hline \multicolumn{4}{|c|}{ Smoking status (Duration) } \\
\hline Non - smoker & 1 & - & \multirow{4}{*}{$<0.000^{*}$} \\
\hline Current smokers ( $<5$ years) & 4.3 & $1.9-12.4$ & \\
\hline Current smokers $(5-10$ years $)$ & 6.9 & $2.8-15.8$ & \\
\hline Current smokers ( $>10$ years) & 10.5 & $4.7-23.6$ & \\
\hline \multicolumn{4}{|c|}{ Smoking frequency (Pack/ day) } \\
\hline$<5$ & 1 & - & \multirow{3}{*}{$<0.000^{*}$} \\
\hline $5-10$ & 5.8 & $2.2-10.8$ & \\
\hline$>10$ & 10.9 & $5.8-34.7$ & \\
\hline
\end{tabular}

$\mathrm{OR}^{*}$ adjusted odd ratio to female, 40 -50 years, brushing more than twice daily, normal periodontal conditions, no oral appliance, non-smokers and smoke less than 5 packs per day. 
$34.3 \%$ ) among epithelial dysplasia and OSCC groups. Significance difference was found $(p<0.000)$. By evaluation the presence of prosthodontic appliances, only $12 \%$ and $14.2 \%$ from cases with epithelial dysplasia and OSCC had no appliances, compared with $(82.5 \%)$ among the control cases. Significant difference was found $(\mathrm{p}<0.000)$. Among cases $(52 \%$ and $48.7 \%)$ were recorded as current smoking more than 10 years, on the other hand $(70.8 \%)$ of the control group was non-smokers, significant difference was found between them $(p<0.000)$. Number of cigarette packs consumed per day was very high $(64 \%$ and $62.9 \%)$ among cases with epithelial dysplasia and OSCC respectively with significance difference $(\mathrm{p}<0.000)$ between them and control group $(11.7 \%)$. (Table 1).

Table (2) showing the multiple logistic regression model with adjusted odds ratio, it had been showed that current smokers in addition to increasing the number of smoking frequencies per day had high risk to epithelial dysplasia or OSCC than non-smokers $(\mathrm{p}<0.000)$. Non using oral hygiene practice considered one of major risk factor to oral cancer $(\mathrm{p}<0.000)$. Tooth mobility to health (5.9:1) ratio and sever periodontitis (3.8:1) which were considered risk factors to epithelial dysplasia or OSCC. Males showed high risk epithelial dysplasia or OSCC than females (1:1.9), with significant $\mathrm{p}$ value (0.05). Low educational level considered risk factor $(\mathrm{p}$ value $=0.01)$ while presence of prosthodontic appliance had no relation to epithelial dysplasia or OSCC formation $\mathrm{p}$ value $(0.09)$. Increasing in age had no effect on oral cancer $(\mathrm{p}$ value $=$ $0.09)$.

Table (3 and 4), showing the staining intensity expressed as (weak, moderate and high) and their distribution in the tissue. P53 immunostaining was evaluated in normal oral mucosa collected from control group, there was a weak expression (100 \%) of P35 which localized in the basal layer among $(20 \%)$, basal and para basal layers among $(80 \%)$ of them (figure1). Regarding the cases of epithelial dysplasia, it was observed that the nuclear expression

Table 3. Staining intensity of P53, CD4 and CD8 among control group, epithelial dysplasia and OSCC cases.

\begin{tabular}{|c|c|c|c|c|}
\hline & $\begin{array}{c}\text { Control } \\
\text { N (\%) } \\
(60)\end{array}$ & $\begin{array}{c}\text { Epi dysplasia } \\
\text { N (\%) } \\
(25)\end{array}$ & $\begin{array}{c}\text { OSCC } \\
\text { N (\%) } \\
(35)\end{array}$ & $P$ value \\
\hline \multicolumn{5}{|c|}{ P53 } \\
\hline Weak & $60(100 \%)$ & $15(60 \%)$ & - & \multirow{3}{*}{$<0.000^{*}$} \\
\hline Moderate & - & - & - & \\
\hline Strong & - & $10(40 \%)$ & $35(100 \%)$ & \\
\hline \multicolumn{5}{|c|}{ CD4 } \\
\hline Weak & $60(100 \%)$ & - & $4(11.4 \%)$ & \multirow{3}{*}{$<0.000$} \\
\hline Moderate & - & $13(52 \%)$ & $4(11.4 \%)$ & \\
\hline Strong & - & $12(48 \%)$ & $27(77.2)$ & \\
\hline \multicolumn{5}{|c|}{ CD8 } \\
\hline Weak & $60(100 \%)$ & $3(12 \%)$ & - & \multirow{3}{*}{$0.01^{*}$} \\
\hline Moderate & - & $8(32 \%)$ & $22(62.9 \%)$ & \\
\hline Strong & - & $14(56 \%)$ & $13(37.1 \%)$ & \\
\hline
\end{tabular}

Table 4. Staining distribution of p53, CD4 and CD8 among control group, epithelial dysplasia and OSCC cases.

\begin{tabular}{|c|c|c|c|}
\hline & $\begin{array}{c}\text { Control } \\
\text { N (\%) } \\
(\mathbf{6 0 )}\end{array}$ & $\begin{array}{c}\text { Epi dyspla- } \\
\text { sia } \\
\mathbf{N}(\mathbf{\%}) \\
\mathbf{( 2 5 )}\end{array}$ & $\begin{array}{c}\text { OSCC } \\
\text { N (\%) } \\
\mathbf{( 3 5 )}\end{array}$ \\
\hline \multicolumn{4}{|c|}{ Stain distribution (P53) } \\
\hline Basal & $12(20 \%)$ & $7(28 \%)$ & - \\
\hline Basal and para basal & $48(80 \%)$ & $18(72 \%)$ & $35(100 \%)$ \\
\hline Invasive in the tumor & - & - & $35(100 \%)$ \\
\hline \multicolumn{5}{|c|}{ Stain distribution (CD4) } \\
\hline Subepithelial stroma & $60(100 \%)$ & $25(100 \%)$ & Surrounded by tumor \\
\hline \multicolumn{5}{|c|}{ Stain distribution (CD8) } \\
\hline Subepithelial stroma & $60(100 \%)$ & $25(100 \%)$ & Surrounded by tumor \\
\hline
\end{tabular}


of P53 was localized to basal (28\%) basal plus parabasal layers of oral epithelium (72\%). There was a correlation of P53 expression with dysplasia's histological grade. In mild and moderate dysplasia cases, there was a weak expression $(60 \%)$. Moreover, in severe dysplasia, there was strong nuclear expression (40\%) with no record for moderate expression (figure 2). As regard to OSCC, all cases $(100 \%)$ showed strong immune-positive reaction to P53, strong nuclear staining were observed in cancer nests of moderately and well-differentiated OSCC mostly in the peripheral cells and localized in the individually scattered epithelial cells of poorly differentiated OSCC (figure3). Significant difference was found between the control group and epithelial dysplasia and OSCC group $(\mathrm{p}<0.000)$.

Regarding CD4 immunostaining evaluation (figures 4,5), the normal mucosa among the control group showed weak expression of CD4 positive cells in the subepithelial stroma (100\%). On the other hand, among epithelial dysplasia cases, $T$ cells formed a subepithelial infiltrate by $(100 \%)$ which varied from moderate $(52 \%)$ to strong and $(48 \%)$ increase with the severity of epithelial dysplasia. In OSCC, CD 4 positive cells were present $(100 \%)$ in the stroma surrounded by the tumor tissue and were significantly more abundant in comparison with epithelial dysplasia. The CD4 staining were expressed by (11.4\% weak, $11.4 \%$ moderate and $77.2 \%$ was strong). Significant difference was found between staining intensity among control and cases of epithelial dysplasia and OSCC (p $<0.000$ ) regarding CD4 expression.
By evaluating CD8 immunostaining, CD8 positive cells showed weak distribution $(100 \%)$ in subepithelial stroma of normal tissue in control group. Among the epithelial dysplasia cases the intensity was ranged from weak expression $(12 \%)$, moderate $(32 \%)$ and high $(56 \%)$ for CD8 with $(100 \%)$ distribution in subepithelial stroma. Similarly, the cases of OSCC expressed by $(100 \%)$ positive CD8 in subepithelial stroma surrounding the tumor with only moderate $(62.6 \%)$ and strong $(37.1 \%)$ expression of CD8 positive cells (figure6). Significance difference between control group, epithelial dysplasia and OSCC regarding CD8 expression was found ( $\mathrm{p}=0.01)$.

\section{Discussion}

The present study was designed as a case-control study which able to study rare diseases using a small number of individuals and have some logistical advantages over clinical trials or cohort study. The number of control group was increased by four ratios than the cases to increase the statistical confidence.

The results of this study showed that males were significant higher risk to develop OSCC than females (OR1.9), this was explained by the effect of other related risk factors to oral cancer as smoking and oral hygiene habits which were evident among males [2, $3,17]$. The present study showed no significant relation of OSCC with the selected age group. This may be explained by the study's selection of age groups was from 40 years and above, as this age range was reported in most studies as age related factor to develop

Figure 1. Weak expression of P53 in basal and para basal layers in normal oral mucosa. (streptavidin-biotin $\times 200$ ).

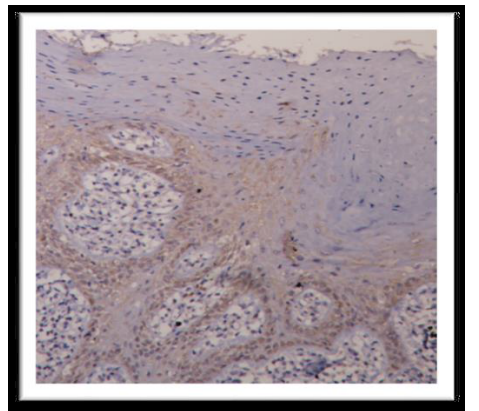

Figure 2. Expression of p53 in epithelial dysplasia, (A): weak expression of P53 in mild dysplasia. (B) \&(C): strong nuclear expression of P53 in sever epithelial dysplasia in basal and para basal layers. (streptavidin-biotin Ax100 B $\times 200 \&$ Cx400).
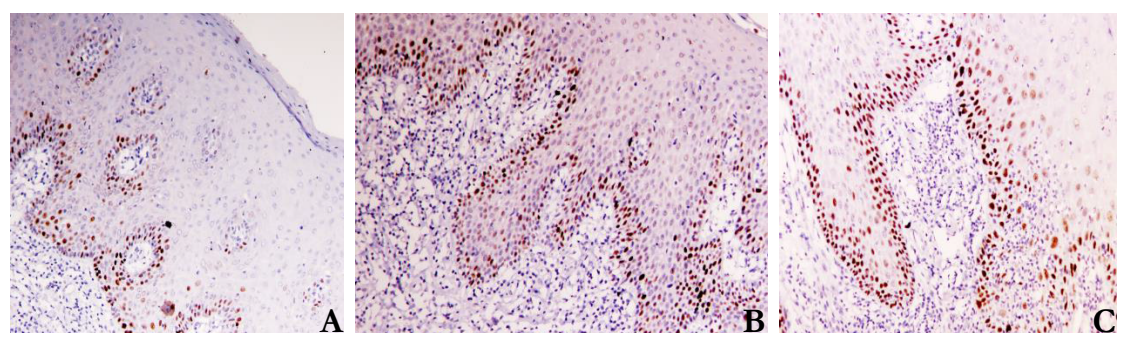

Figure 3. Strong nuclear staining of P53 were observed in cancer nests of well-differentiated OSCC (A) and localized in the individually scattered epithelial cells of poorly differentiated OSCC (B). (streptavidin-biotin A×200\&Bx400).

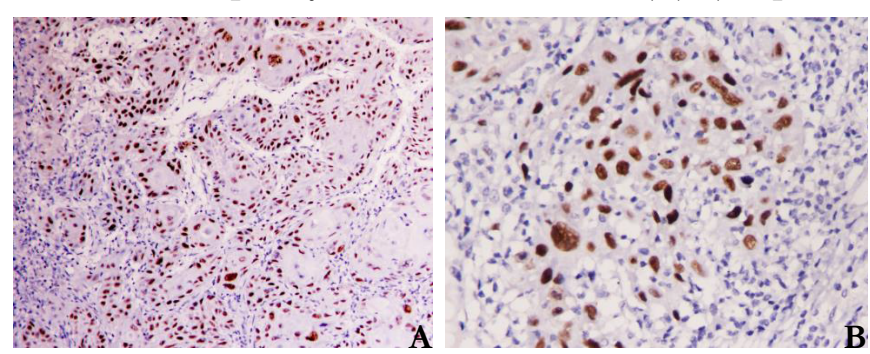


Figure 4. (A): Weak expression of CD4 positive T cells in the subepithelial stroma of normal oral mucosa. Strong expression of CD4 increase from moderate to severe dysplasia (B \& C). (streptavidin-biotin A×100 and B \& C x 200).
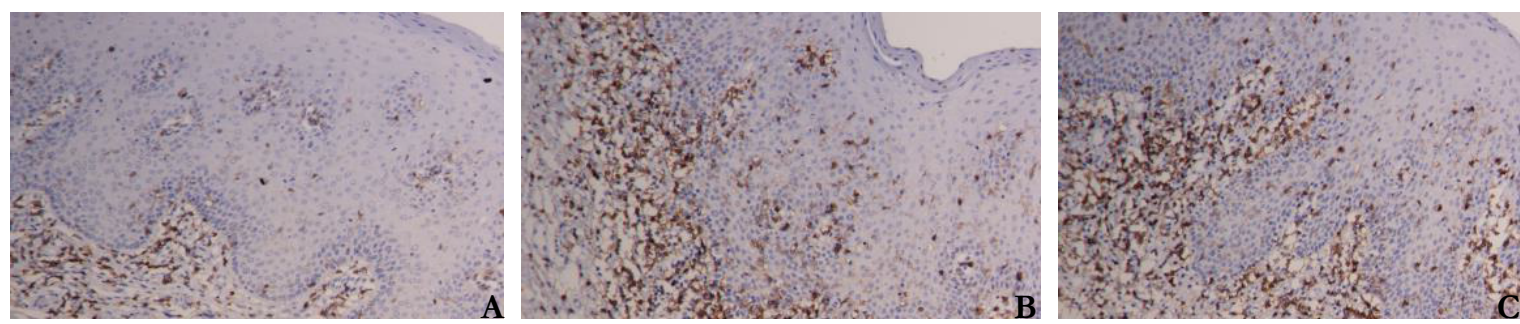

Figure 5. (A\&B): Strong expression of CD4 positive $T$ cells in the stroma surrounded by the tumor tissue in OSCC.

(streptavidin-biotin $\mathrm{A} \times 100 \& \mathrm{Bx} 200$ ).
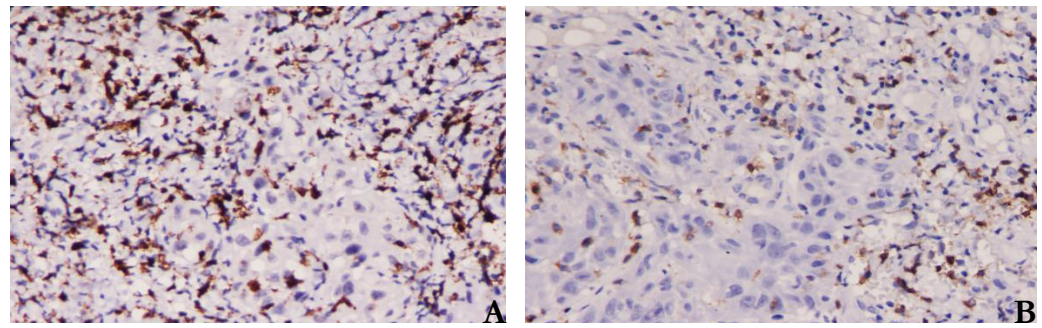

Figure 6. (A): Strong expression of CD8 +T cells in the subepithelial stroma in severe epithelial dysplasia. (B): strong expression of CD8+ in the stroma surrounded by the tumor tissue in OSCC. (streptavidin-biotin A \& B x 200).
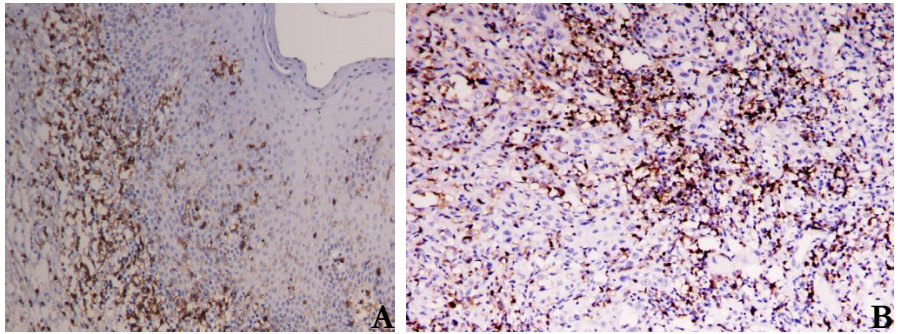

OSCC $[18,19]$. Low educational level showed higher significant association to OSCC compared with those reported with moderate and high educational level. These may attribute to the indirect relation between educational level and patient oral hygiene status or the awareness to early signs detection of oral cancer $[20,21]$.

The present study showed that smoking was major risk factor to OSCC by 10.5 folders than non-smokers and the duration of smoking affect the high frequency of oral cancer. Studies had been proven that the use of tobacco is associated with the development of OSCC. Tobacco can cause epigenetic alteration of oral epithelial cells, inhibit multiple systemic immune functions of the host and its toxic metabolites might cause oxidative stress on tissues which induce OSCC $[2,4,20]$. Bad oral hygiene showed significant association with OSCC (OR 4.3) folder than that with good oral hygiene $(\mathrm{p}<0.000)$. Many studies showed association between irregular tooth brushing and oral cancer $[2,5]$. Presence of prosthodontic appliance showed no significance association with OSCC was observed in the present study which coincidence with other studies $[3,21]$. The risk of OSCC was statistically significantly higher among patients either with tooth mobility or sever periodontitis of (OR 5.9, 3.8) compared with patients with moderate or mild periodontitis.

The concept of cancer immuno editing provides a chance to view the dynamic interaction between the immune system and dysplastic cells/tumor cells, with phases of elimination, equilibrium and escape [22]. The role of immune response in premalignant disorders is not so well clarified [23]. The immune system has the capacity to eliminate cells with DNA damage; which have the potential to undergo malignant transformation, in the early phase of cell dysplasia or early tumor cell formation [23].

In this study, the general finding was that severe pathological changes in epithelial tissues (moderate and severe dysplasia or OSCC) are accompanied by a higher level of the immune infiltrate of CD4+\&CD8+ when compared to lesions with mild dysplasia and among control group.

There was a significantly increased level of the immune infiltrate of CD4 + cells in OSCC group as compared to epithelial dysplasia and control group, confirmed by the association between inflammatory mononuclear cell infiltrates and oral premalignant lesions or OSCC [24]. Other studies revealed that CD4 positive cells increased in number when the lesion became malignant as compared to normal mucosa and dysplastic lesions [25, 26].

The results of the present study showed that the level of CD8+ cells in OSCC were higher than CD8+ cells in dysplastic lesions and controls, which might indicate that the cytotoxic response was increased in the malignant state. These results were consistent with the results of Gannot et.al 2002, which revealed that in the tongue lesions, the changes in the epithelium from normal appearance were accompanied by a corresponding increase in the infiltration of CD4, CD8, CD14, CD19+20, and HLA/DR positive cells [27]. On the other hand, Rita et.al (1996) examined head and neck cancers for immune inhibitory factors and found that IL-10, together with TGF-b and prostaglandins, were associated with a reduced content of CD8+ cells [28]. 
The finding of the present study could be explained by previous report in which CD8+ cells in OSCC were higher than CD8+ cells in dysplastic lesions and controls. Kumagai et.al [29] explained that the action of cytotoxic CD8+cells in the immune responses could inhibit the aggressiveness of malignant cells and that the CD8+cells can recognize and kill potentially malignant cells. In this respect, some studies considered the increased amount of CD8+cells as an independent favorable prognostic factor in different types of cancer [30-32]. P53 functions as a key tumor suppressor as it plays an important role in apoptosis, genomic stability, and inhibition of angiogenesis. In this study, the lesions with the OSCC phenotype showed a higher expression of P53 when compared to epithelial dysplasia group. In normal oral epithelium, P53 expression was weak in the basal and parabasal cell layers. There was a correlation of P53 expression with dysplasia's histological grade. Significant difference was noticed between severe dysplasia and the other two types of dysplasia. In addition, a significant increase of P53 expression of the epithelial cells in OSCC compared to ED was noted. Immuno expression of P53 in transformed oral epithelium may be prognostic risk factor of malignant disorders independent on dysplastic changes, however, further studies with follow up are important to confirm this presumption.

Our results were in accordance to previous studies which suggested that the immunolocalization of P53 protein may occur at the very early stages of development of OSCC [33, 34]. A study by Cruz et.al. revealed that suprabasal P53 immuno expression patterns are associated with high grades of dysplasia and correlate with progress to oral squamous cell carcinoma. The authors concluded that the expression pattern should be considered a marker for prediction of the malignant transformation, although malignant transformation also may occur in the absence of suprabasal P53 expression or dysplastic changes [35]. In this study, there was no significant relationship between the intensity P53 expression and the different grades of OSCC, This finding was confirmed by the previous studies which report no relation between P53 immuno expression with the differentiation grade of OSCC $[36,37]$.

Generally, the study results showed that increase P53 expression is significantly correlated with the expression of CD4 and CD8 in the epithelial dysplastic lesions and OSCC. The results of present study were coincidence with the finding of other study which had focused on the increase in CD8 cytotoxic $\mathrm{T}$ cell in response to P53. The CD 8 cytotoxic $T$ cell have been shown to recognize and kill a variety of tumor cell lines including SCC lines [38]. On the other hand, CD4 T cells from normal individuals and cancer patients have been shown to recognize peptides derived from the core domain of P53 [39].CD4 T cells infiltrate the tumors and have been suggested to play a role in tumor regression [40].

\section{Conclusion}

The most detected risk factors related to OSCC were the frequency and duration of smoking, bad oral hygiene, sever periodontitis and low educational level. Public awareness is needed among these targeted groups to prevent oral cancer. The increase in the expression of $\mathrm{CD} 4+, \mathrm{CD} 8+$ with epithelial transformation from normal to dysplastic or squamous cell carcinoma and its correlation with the over expression of P53 may have a potential significant role as biological markers of malignant transformation and carcinogenesis, and it could potentially be utilized in the treatment of oral squamous cell carcinoma.

\section{References}

[1]. Siegel R, Ma J, Zou Z, Jemal A. Cancer statistics, 2014. CA: a cancer journal for clinicians. 2014 Jan 7;64(1):9-29.

[2]. Kumar M, Nanavati R, Modi TG, Dobariya C. Oral cancer: Etiology and risk factors: A review. J Cancer Res Ther. 2016 Apr-Jun;12(2):458-63. Pubmed PMID: 27461593.

[3]. Marques LA, Eluf-Neto J, Figueiredo RA, Góis-Filho JF, Kowalski LP, Carvalho $\mathrm{MB}$, et al. Oral health, hygiene practices and oral cancer. Rev Saude Publica. 2008 Jun;42(3):471-9. Pubmed PMID: 18470367.

[4]. Balaram P, Sridhar H, Rajkumar T, Vaccarella S, Herrero R, Nandakumar A, et al. Oral cancer in southern India: the influence of smoking, drinking, paan-chewing and oral hygiene. Int J Cancer. 2002 Mar 20;98(3):440-5. Pubmed PMID: 11920597.

[5]. Abnet CC, Kamangar F, Islami F, Nasrollahzadeh D, Brennan P, Aghcheli K, et al. Tooth loss and lack of regular oral hygiene are associated with higher risk of esophageal squamous cell carcinoma. Cancer Epidemiol Biomarkers Prev. 2008 Nov;17(11):3062-8. Pubmed PMID: 18990747.

[6]. Liu SC, Klein-Szanto AJ. Markers of proliferation in normal and leukoplakic oral epithelia. Oral Oncol. 2000 Mar;36(2):145-51. Pubmed PMID: 10745166.

[7]. Leemans CR, Braakhuis BJ, Brakenhoff RH. The molecular biology of head and neck cancer. Nat Rev Cancer. 2011 Jan;11(1):9-22. Pubmed PMID: 21160525.

[8]. Chin D, Boyle GM, Williams RM, Ferguson K, Pandeya N, Pedley J, et al. Novel markers for poor prognosis in head and neck cancer. Int J Cancer. 2005 Feb 20;113(5):789-97. Pubmed PMID: 15499618.

[9]. Zou W. Immunosuppressive networks in the tumour environment and their therapeutic relevance. Nat Rev Cancer. 2005 Apr;5(4):263-74. Pubmed PMID: 15776005

[10]. Dranoff G. Cytokines in cancer pathogenesis and cancer therapy. Nat Rev Cancer. 2004 Jan;4(1):11-22. Pubmed PMID: 14708024.

[11]. Bergmann C, Strauss L, Wang Y, Szczepanski MJ, Lang S, Johnson JT, et al. $T$ regulatory type 1 cells in squamous cell carcinoma of the head and neck: mechanisms of suppression and expansion in advanced disease. Clin Cancer Res. 2008 Jun 15;14(12):3706-15. Pubmed PMID: 18559587.

[12]. Badoual C, Hans S, Rodriguez J, Peyrard S, Klein C, Agueznay Nel H, et al. Prognostic value of tumor-infiltrating CD4+ T-cell subpopulations in head and neck cancers. Clin Cancer Res. 2006 Jan 15;12(2):465-72. Pubmed PMID: 16428488.

[13]. Öhman J, Magnusson B, Telemo E, Jontell M, Hasséus B. Langerhans cells and $\mathrm{T}$ cells sense cell dysplasia in oral leukoplakias and oral squamous cell carcinomas--evidence for immunosurveillance. Scand J Immunol. 2012 Jul;76(1):39-48. Pubmed PMID: 22469080.

[14]. Costa NL, Gonçalves AS, Souza-Lima NC, Jaime-Paiva LG, JunqueiraKipnis AP, Silva TA, et al. Distinct expression of perforin and granzyme B in lip and oral cavity squamous cell carcinoma. J Oral Pathol Med. 2011 May;40(5):380-4. Pubmed PMID: 21342273.

[15]. Russell AL. The Periodontal Index. J Periodontol. 1967 NovDec;38(6):Suppl:585-91. Pubmed PMID: 5237681

[16]. Barnes L, Eveson JW, Sidransky D, Reichart P, editors. Pathology and genetics of head and neck tumours. IARC; 2005.

[17]. Jiang X, Wu J, Wang J, Huang R. Tobacco and oral squamous cell carcinoma: A review of carcinogenic pathways. Tob Induc Dis. 2019 Apr 12;17:29. Pubmed PMID: 31582940.

[18]. Llewellyn CD, Johnson NW, Warnakulasuriya KA. Risk factors for squamous cell carcinoma of the oral cavity in young people--a comprehensive literature review. Oral Oncol. 2001 Jul;37(5):401-18. Pubmed PMID: 11377229.

[19]. Moore SR, Johnson NW, Pierce AM, Wilson DF. The epidemiology of mouth cancer: a review of global incidence. Oral Dis. 2000 Mar;6(2):65-74. Pubmed PMID: 10702782 .

[20]. Franco EL, Kowalski LP, Oliveira BV, Curado MP, Pereira RN, Silva ME, et al. Risk factors for oral cancer in Brazil: a case-control study. Int J Cancer. 1989 Jun 15;43(6):992-1000. Pubmed PMID: 2732011.

[21]. Llewellyn CD, Johnson NW, Warnakulasuriya KA. Risk factors for oral cancer in newly diagnosed patients aged 45 years and younger: a case-control study in Southern England. J Oral Pathol Med. 2004 Oct;33(9):525-32. Pubmed PMID: 15357672.

[22]. Dunn GP, Old LJ, Schreiber RD. The three Es of cancer immunoediting. Annu Rev Immunol. 2004;22:329-60. Pubmed PMID: 15032581.

[23]. Zitvogel L, Tesniere A, Kroemer G. Cancer despite immunosurveillance: 
immunoselection and immunosubversion. Nat Rev Immunol. 2006 Oct;6(10):715-27. Pubmed PMID: 16977338.

[24]. Migliorati CA, Migliorati EK, Silverman S Jr, Greenspan D, Greenspan JS. Phenotypic identification of mononuclear cells in oral premalignant lesions and cancer by monoclonal antibodies. J Oral Pathol. 1986 Jul;15(6):352-8. Pubmed PMID: 3093654

[25]. Hirota J, Ueta E, Osaki T, Ogawa Y. Immunohistologic study of mononuclear cell infiltrates in oral squamous cell carcinomas. Head Neck. 1990 Mar-Apr;12(2):118-25. Pubmed PMID: 2179166.

[26]. Vetto JT, Lum S, Morris A, Sicotte M, Davis J, Lemon M, et al. Presence of the T-cell activation marker OX-40 on tumor infiltrating lymphocytes and draining lymph node cells from patients with melanoma and head and neck cancers. Am J Surg. 1997 Sep;174(3):258-65. Pubmed PMID: 9324133.

[27]. Gannot G, Gannot I, Vered H, Buchner A, Keisari Y. Increase in immune cell infiltration with progression of oral epithelium from hyperkeratosis to dysplasia and carcinoma. Br J Cancer. 2002 May 6;86(9):1444-8. Pubmed PMID: 11986779.

[28]. Young MR, Wright MA, Lozano Y, Matthews JP, Benefield J, Prechel MM. Mechanisms of immune suppression in patients with head and neck cancer: influence on the immune infiltrate of the cancer. Int J Cancer. $1996 \mathrm{Jul}$ 29;67(3):333-8. Pubmed PMID: 8707405.

[29]. Kumagai K, Hamada Y, Gotoh A, Kobayashi H, Kawaguchi K, Horie A, et al. Evidence for the changes of antitumor immune response during lymph node metastasis in head and neck squamous cell carcinoma. Oral Surg Oral Med Oral Pathol Oral Radiol Endod. 2010 Sep;110(3):341-50. Pubmed PMID: 20598595.

[30]. Piersma SJ, Jordanova ES, van Poelgeest MI, Kwappenberg KM, van der Hulst JM, Drijfhout JW, et al. High number of intraepithelial CD8+ tumorinfiltrating lymphocytes is associated with the absence of lymph node metastases in patients with large early-stage cervical cancer. Cancer Res. 2007 Jan 1;67(1):354-61. Pubmed PMID: 17210718

[31]. Cho Y, Miyamoto M, Kato K, Fukunaga A, Shichinohe T, Kawarada Y, et al. CD4+ and CD8+ T cells cooperate to improve prognosis of patients with esophageal squamous cell carcinoma. Cancer Res. 2003 Apr 1;63(7):1555-9. Pubmed PMID: 12670904.
[32]. Galon J, Costes A, Sanchez-Cabo F, Kirilovsky A, Mlecnik B, Lagorce-Pagès $\mathrm{C}$, et al. Type, density, and location of immune cells within human colorectal tumors predict clinical outcome. Science. 2006 Sep 29;313(5795):1960-4. Pubmed PMID: 17008531.

[33]. Rowley H, Helliwell TR, Jones AS, Roland NJ, Field EA, Field JK. An immunohistochemical analysis of $\mathrm{p} 53$ protein expression in pre-malignant and malignant tissues of the oral cavity. Clin Otolaryngol Allied Sci. 1997 Feb;22(1):23-9. Pubmed PMID: 9088674.

[34]. Slootweg PJ, Koole R, Hordijk GJ. The presence of $\mathrm{p} 53$ protein in relation to $\mathrm{Ki}-67$ as cellular proliferation marker in head and neck squamous cell carcinoma and adjacent dysplastic mucosa. Eur J Cancer B Oral Oncol. 1994;30B(2):138-41. Pubmed PMID: 8032302.

[35]. Cruz I, Napier SS, van der Waal I, Snijders PJ, Walboomers JM, Lamey $\mathrm{PJ}$, et al. Suprabasal p53 immunoexpression is strongly associated with high grade dysplasia and risk for malignant transformation in potentially malignant oral lesions from Northern Ireland. J Clin Pathol. 2002 Feb;55(2):98104. Pubmed PMID: 11865002.

[36]. de Oliveira LR, Ribeiro-Silva A, Zucoloto S. Prognostic impact of p53 and p63 immunoexpression in oral squamous cell carcinoma. J Oral Pathol Med. 2007 Apr;36(4):191-7. Pubmed PMID: 17391296.

[37]. Gasco M, Crook T. The p53 network in head and neck cancer. Oral Oncol. 2003 Apr;39(3):222-31. Pubmed PMID: 12618194.

[38]. Sharma P, Shen Y, Wen S, Yamada S, Jungbluth AA, Gnjatic S, et al. CD8 tumor-infiltrating lymphocytes are predictive of survival in muscle-invasive urothelial carcinoma. Proc Natl Acad Sci U S A. 2007 Mar 6;104(10):396772. Pubmed PMID: 17360461.

[39]. Fujita H, Senju S, Yokomizo H, Saya H, Ogawa M, Matsushita S, et al. Evidence that HLA class II-restricted human CD4+ T cells specific to p53 self peptides respond to $\mathrm{p} 53$ proteins of both wild and mutant forms. Eur J Immunol. 1998 Jan;28(1):305-16. Pubmed PMID: 9485210.

[40]. Patel A, Halliday GM, Barnetson RS. CD4+ T lymphocyte infiltration correlates with regression of a UV-induced squamous cell carcinoma. J Dermatol Sci. 1995 Jan;9(1):12-9. Pubmed PMID: 7727352. 